\title{
Analysis of twenty-four hour heart rate variability in patients with panic disorder
}

\author{
Rollin McCraty ${ }^{\mathrm{a}, *}$, Mike Atkinson ${ }^{\mathrm{a}}$, Dana Tomasino ${ }^{\mathrm{a}}$, \\ William P. Stuppy ${ }^{b}$

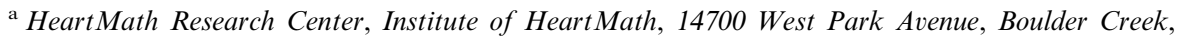 \\ CA 95006, USA \\ b 1136 West 6th Street, Suite 401, Los Angeles, CA 90017, USA
}

Received 9 May 2000; received in revised form 20 October 2000; accepted 30 January 2001

\begin{abstract}
Growing evidence suggests that alterations in autonomic function contribute to the pathophysiology of panic disorder (PD). This retrospective study employed 24-h heart rate variability (HRV) analysis of Holter records to compare autonomic function in PD patients $(n=38)$ with healthy, age- and gender-matched controls. Both time and frequency domain measures were calculated, and a circadian rhythm analysis was performed. The SDNN index, 5-min total power, very low frequency (VLF) and low frequency (LF) power were significantly lower in panic patients relative to controls over the 24-h period. Hourly means were significantly lower during some of the waking hours as well as the latter part of the sleep cycle. In contrast, the mean RR interval, RMSSD and high frequency (HF) power were comparable in patients and controls. Results suggest that sympathetic activity is depressed in PD patients under usual life conditions, leading to a relative predominance of vagal tone. Findings of low HRV in PD patients are consistent with the high rate of cardiovascular morbidity and mortality in this population, as well as with the emerging view of panic as a disorder involving reduced flexibility and adaptability across biological, affective and behavioral dimensions. (C) 2001 Elsevier Science B.V. All rights reserved.
\end{abstract}

Keywords: Heart rate variability (HRV); Panic disorder; Autonomic nervous system; Autonomic function; Circadian rhythms

* Corresponding author. Tel.: + 1-831-338-8727; fax: + 1-831-338-1182.

E-mail address: rollin@heartmath.org (R. McCraty). 


\section{Introduction}

The high prevalence and severe impact on quality of life of panic disorder (PD) make this condition one of the most studied psychological disorders in the US (Weissman, 1991). Patients with panic disorder experience recurrent panic attacks, which are characterized by episodes of intense anxiety accompanied by a range of alarming somatic symptoms including chest pain, heart pounding, tachycardia, shortness of breath, sweating and dizziness. Collectively, these responses are suggestive of autonomic nervous system (ANS) dysfunction.

A number of recent investigations have sought to illuminate the autonomic underpinnings of PD using the analysis of heart rate variability (HRV), a noninvasive, sensitive and dynamic indicator of autonomic regulation of the heart. Low heart rate variability is found in individuals with a wide range of pathologies and is considered a powerful predictor of heart disease, increased risk of sudden death, as well as all-cause mortality (Öri et al., 1992; Tsuji et al., 1994, 1996; Dekker et al., 1997). Recently, measurements of HRV have also been increasingly applied to investigate autonomic regulation in affective disorders, and aberrant HRV patterns have been observed in various conditions including anxiety and major depression (Dalack and Roose, 1990; Rechlin et al., 1994; Thayer et al., 1996).

The majority of studies of HRV in panic disorder patients have focused on short-term resting recordings and/or autonomic responses to short-term challenges, such as cold pressor, postural change, sodium lactate infusion and various pharmacological treatments. Generally, this body of research indicates reduced overall HRV, diminished vagal tone and relative sympathetic dominance in PD patients under these types of conditions (Yeragani et al., 1990, 1991, 1993, 1994; Friedman et al., 1993; Klein et al., 1995; Friedman and Thayer, 1998a,b; Hamada et al., 1998). However, with regard to the specific findings of these investigations, some inconsistencies do exist. For example, lowered high frequency (HF) power in panic patients as compared to control subjects in supine or standing postures was demonstrated in some cases (Klein et al., 1995; Seier et al., 1997) but not in others (Yeragani et al., 1993; Middleton et al., 1994; Rechlin et al., 1994). One short-term study showed panic patients to have increased very low frequency (VLF) power relative to controls in the supine posture (Rechlin et al., 1994); another demonstrated no difference in power in this frequency range in the supine condition but found decreased VLF power in patients as compared to controls while standing (Yeragani et al., 1993). One investigation demonstrated decreased short-term low frequency (LF) power in patients (Middleton et al., 1994) while others found no significant difference in power in the LF range between patients and controls (Yeragani et al., 1993; Rechlin et al., 1994). Further, one group reported a decrease in both HF and LF power in PD patients as compared to controls in response to lactate infusions (Seier et al., 1997), whereas other investigators demonstrated a significant decrease only in HF power (Yeragani et al., 1994). Still other research has shown normal autonomic responsivity to a broad range of challenges in PD patients (Stein and Asmundson, 1994). 
While short-term HRV recordings can provide relevant data on autonomic function under specific controlled conditions, an informative contrast to these data can be achieved through the analysis of 24-h ambulatory ECG (Holter) records, which provides a window on individuals' autonomic nervous system activity and balance in the context of their normal day-to-day activities. Advantages of ambulatory monitoring include a longer recording period, monitoring of the ECG in the subject's usual surroundings, the availability of sleep and circadian rhythm data, and a frequency resolution that includes the ultra low frequency (ULF) range. To our knowledge, only one study by Yeragani and colleagues has provided a full analysis of 24-h HRV in panic disorder patients. These authors reported decreased total, ULF and VLF power in PD patients as compared to healthy controls. Patients were found to have normal HF power, which reflects parasympathetic activity (Yeragani et al., 1998).

The present study provides further data on 24-h HRV in PD patients, using a larger sample size and employing time domain as well as frequency domain analysis methods. We also provide a circadian rhythm analysis of the hourly variations in HRV measures during the waking hours and during sleep. The overall aim of this investigation is to add to the existing body of data on autonomic nervous system function and balance in panic disorder, in an effort to characterize possible alterations in autonomic regulation that may underlie a vulnerability to panic attacks.

\section{Methods}

\subsection{Subjects}

In this retrospective study, we analyzed Holter records obtained from 38 patients with panic disorder (mean age 38 years, S.D. $=7.65$; age range $24-54$ years; 20 females and 18 males), and 38 healthy control subjects (mean age 38 years, S.D. = 7.86; age range 22-54 years). Written informed consent for the use of Holter information was obtained from all study participants.

Patients were diagnosed with panic disorder by a psychiatrist on the basis of DSM-IV criteria (American Psychiatric Association, 1994). All patients were symptomatic at the time of assessment and had been referred by a psychiatrist to an internal medicine physician for the purpose of ensuring that their symptoms had no cryptic underlying medical causes (e.g. arrhythmias, gastrointestinal disorders, etc.). These subjects were determined to be free of medical or cardiovascular illness by examination and history, and had no electrocardiogram abnormalities. They had not taken any medication (except for occasional non-opioid analgesics) for a minimum of 30 days prior to Holter recording.

Healthy control subjects, gender- and age-matched to within 2 years of the panic group, were drawn from a large 24-h HRV normals database maintained by the Institute of HeartMath (Umetani et al., 1998). Healthy subjects were defined as those without clinical evidence of organic disease in terms of medical history, 
physical examination and resting 12-lead electrocardiogram. Oral contraceptives, non-opioid analgesics and nonsteroidal anti-inflammatory agents were the only medications allowed. In addition to self-report of general psychological health status, the majority of control group subjects were screened for depression, anxiety and other psychological symptoms using the Brief Symptom Inventory (BSI) (Derogatis, 1993) and the Personal and Organizational Quality Assessment (POQA) survey (Barrios-Choplin and Atkinson, 1996).

\subsection{Measures}

Both time domain and frequency domain (power spectral) analyses were used in this study to assess HRV data. Time domain analysis of Holter recordings employs a variety of measures that provide a statistical analysis of the fluctuations in sinus RR intervals over $24 \mathrm{~h}$ (Kleiger et al., 1992). Collectively, time domain measures quantify how much variability exists in heart rate over a $24-\mathrm{h}$ period. The time domain HRV measures employed in this study were mean heart rate (HR), the standard deviation of all normal sinus RR intervals over $24 \mathrm{~h}$ (SDNN), the standard deviation of all averaged normal sinus intervals for each 5-min segment in the 24-h recording (SDANN), the mean of the standard deviations of all normal sinus RR intervals for all 5-min segments (SDNN index), and the root mean square of successive differences between normal sinus RR intervals (RMS-SD).

Power spectral analysis reduces the HRV signal to its constituent frequency components and quantifies the relative power of these components (Öri et al., 1992). Spectral analysis of HRV using Fast Fourier transformation reveals peaks at several major frequency ranges, which have been defined as the $\mathrm{HF}(0.15-<0.4$ $\mathrm{Hz}), \operatorname{LF}(0.04-<0.15 \mathrm{~Hz}), \operatorname{VLF}(0.0033-<0.04 \mathrm{~Hz})$ and ULF $(0-<0.0033 \mathrm{~Hz})$ regions of the power spectrum (HRV Task Force Report, 1996). The HF component, which is related to respiratory sinus arrhythmia, is widely accepted as a measure of parasympathetic or vagal activity (HRV Task Force Report, 1996). Power in the LF band is related to baroreceptor activity and blood pressure wave activity and resonance, and is dually modulated by the parasympathetic and sympathetic systems (Pomeranz et al., 1985; Malliani, 1995). The ratio of LF/HF power has been used as a marker of sympathovagal balance in some studies (Pagani et al., 1986; Malliani et al., 1991); however, because LF power can reflect both sympathetic and parasympathetic activity, this interpretation can at times be misleading (Eckberg, 1997). Sympathovagal balance can also be approximated by the representation of the LF and HF bands in normalized units, which represent the relative value of each power component in proportion to the total power minus the VLF and ULF components. This representation minimizes the effect of changes in total power on the LF and HF components (Malliani, 1995).

Although the majority of the total power in the 24-h HRV power spectrum is accounted for by the ULF and VLF components, the physiological mechanisms involved in the generation of these rhythms are less defined and still somewhat controversial. The VLF component has been proposed as a marker of sympathetic activity (Saul et al., 1988; Perini et al., 1990), while power in the ULF band is 
believed to reflect long-term regulatory mechanisms related to thermoregulation, the renin-angiotensin system and other humoral factors, as well as circadian rhythms in the autonomic and hormonal systems (Kitney and Rompelman, 1977). The 24-h total power (TP) is highly correlated with power in the ULF band, while a 5-min TP (the combined power in the VLF, LF and HF bands for each 5-min segment, averaged over the 24-h period) provides an indicator of short-term oscillations in ANS activity.

\subsection{Data collection}

Holter records were obtained using three-channel Holter recorders (Del Mar Avionics, Irvine, CA) over a 24 -h time period using standard procedures. Participants were asked to keep a log of various activities in which they engaged during the recording period, including most importantly the time at which they went to sleep and when they woke up. Only subjects who maintained a normal activity level (i.e. work, household activities, etc.) and sleep schedule were included in the study group. The mean start time of the sleep cycle for all subjects was 23:22 h $($ S.D. $=1.26)$ and the mean ending time was $06: 47 \mathrm{~h}($ S.D. $=0.93)$. There was no significant difference in the duration of the sleep cycle between the two groups.

\subsection{Analysis of the data}

The 24-h Holter records were digitized using a model 463 AccuPlus Holter Analyzer (Del Mar Avionics). Each beat was classified and labeled with respect to the site of origin by means of standard Del Mar Avionics algorithms. All recordings were manually overread and corrected by an experienced Holter technician. The $\mathrm{RR}$ interval data were then transferred to a PC computer via computer network for second stage editing, where all nonsinus intervals as well as one RR interval before and two after each nonsinus beat were eliminated. All recordings were $>20 \mathrm{~h}$ in duration and included the entire sleep cycle.

After the second stage of editing, the RR interval power spectrum was computed over the entire recording interval by a method described previously (Bigger et al., 1995). First, a regularly-spaced time series was derived from the RR intervals by sampling the irregularly-spaced series defined by the succession of normal RR intervals. For each Holter ECG recording, $2^{18}$ points were sampled; for recordings precisely $24 \mathrm{~h}$ in duration, the sampling interval was $329 \mathrm{~ms}$. Gaps in the time series resulting from noise or ectopic beats were filled in with linear splines. The power spectral density (PSD) was computed for the $\sim 24$-h recordings. Total power $(<0.4$ $\mathrm{Hz})$ and ULF power $(<0.0033 \mathrm{~Hz})$ were computed by integration over their frequency interval.

The 5-min frequency domain measures were calculated by raveling the resampled time series into 50\% overlapping 5-min segments. A linear detrend was applied to the data segments by first fitting a straight line to each segment (standard least-squares method) and then subtracting it from the data segment. Next, a Hanning window was applied and the PSD was computed and corrected for the 
attenuating effects of the Hanning window. The 5-min frequency domain measures of RR variability were computed by integration over their frequency intervals. We calculated the power within three frequency bands of the RR interval power spectrum: (1) VLF power $(0.0033-<0.04 \mathrm{~Hz})$; (2) LF power $(0.04-<0.15 \mathrm{~Hz})$; and (3) $\mathrm{HF}$ power $(0.15-<0.4 \mathrm{~Hz})$. In addition, we calculated 5-min total power (power in the band $<0.4 \mathrm{~Hz}$ ) and the ratio of $\mathrm{LF}$ to $\mathrm{HF}$ power ( $\mathrm{LF} / \mathrm{HF}$ ratio). Time domain measures of RR variability were computed as described in Section 2.2 above.

Daytime circadian rhythm values were calculated by taking the mean of the individual 5-min values for each hour of the day (09:00-20:00 h). For this study, the sleep cycle began $30 \mathrm{~min}$ after the subject's diary noted going to sleep and ended $30 \mathrm{~min}$ before waking. Since the duration, start and end times of the subjects' sleep cycles varied, the sleep cycles were normalized across six equal-length epochs. The 5-min HRV values for each subject were distributed into the six epochs and the average values for each epoch were calculated.

The 1-h interval from 10:00-10:59 $\mathrm{h}$ was removed from analysis, since this was the time when most of the panic subjects were connected to the Holter recorder, as well as when most were disconnected; thus, much of the data during this hour was not obtained. The hook-up times for the control subjects varied greatly and did not present a problem for analysis; however, their 10:00-10:59 $\mathrm{h}$ values were removed from analysis since no comparison to the panic subjects could be made.

\subsection{Statistical analysis}

To achieve greater statistical power and calculate meaningful averages, time and frequency domain variables with a skewness coefficient $>1.0$ were logarithmically transformed as described elsewhere (Bigger et al., 1995). The 24-h, daytime, nighttime, and night-day difference variables for the two groups, panic and control, were compared using single factor ANOVA. Differences were considered significant at $P<0.05$. Repeated measures ANOVA was used to analyze the hourly average values for the two groups. We used panic versus controls as the grouping factor and time as the repeated measures factor. Sidak's post hoc multiple comparison test was used for multiple comparisons on the time factor. When there was a significant group versus time interaction effect, we separately compared each hourly average value between the two groups using single factor ANOVA. Correction for multiple comparisons was performed using the Student-Newman-Keuls (SNK) test.

\section{Results}

\subsection{Twenty-four hour HRV measures}

Table 1 and Fig. 1 compare mean values for all time and frequency domain HRV measures over the total 24 -h recording period for PD patients and healthy age- and gender-matched controls. 


\subsubsection{Time domain measures}

There was no significant difference in the mean RR interval (heart rate) or in the RMS-SD between patients and controls. The SDNN tended to be lower in panic patients, but this difference did not reach significance $(P=0.08)$. The SDNN index was significantly lower over the $24 \mathrm{~h}$ in the PD patients $(P<0.05)$.

\subsubsection{Frequency domain measures}

In PD patients, 5-min total power, VLF and LF power were significantly lower than in healthy controls $(P<0.01)$. The $\mathrm{LF} / \mathrm{HF}$ ratio and normalized LF power were also significantly lower in PD patients, whereas normalized HF power was significantly higher in the patients $(P<0.001)$. Total power $(P=0.06)$ and ULF power $(P=0.08)$ tended to be lower in the panic patients, although differences did not reach significance. There was no significant difference in HF power between the two groups.

Table 1

Time and frequency domain measures of 24-h HRV in panic patients and healthy controls ${ }^{\mathrm{a}}$

\begin{tabular}{|c|c|c|c|}
\hline & \multicolumn{2}{|l|}{ Total record $(\sim 24 \mathrm{~h})$} & \multirow[t]{2}{*}{$P<$} \\
\hline & $\begin{array}{l}\text { Panic patients }(n=38) \\
\text { Mean } \pm \text { S.D. }\end{array}$ & $\begin{array}{l}\text { Controls }(n=38) \\
\text { Mean } \pm \text { S.D. }\end{array}$ & \\
\hline Mean heart rate (BPM) & $78.70 \pm 10.19$ & $79.84 \pm 8.25$ & - \\
\hline Mean RR interval (ms) & $795.49 \pm 99.14$ & $785.12 \pm 82.31$ & ns \\
\hline SDNN (ms) & $126.38 \pm 32.01$ & $139.91 \pm 35.42$ & $\mathrm{~ns}$ \\
\hline SDANN (ms) & $110.98 \pm 30.53$ & $123.82 \pm 34.91$ & ns \\
\hline SDNN index (ms) & $56.17 \pm 15.33$ & $63.75 \pm 14.91$ & 0.05 \\
\hline RMS-SD (ms) & $34.32 \pm 15.76$ & $32.13 \pm 11.82$ & \\
\hline Ln (RMS-SD) & $3.43 \pm 0.47$ & $3.41 \pm 0.36$ & ns \\
\hline Total power $\left(\mathrm{ms}^{2}\right)$ & $16663.96 \pm 8064.65$ & $21080.87 \pm 11173.83$ & \\
\hline Ln (total power) & $9.60 \pm 0.53$ & $9.83 \pm 0.51$ & ns \\
\hline $\mathrm{ULF}\left(\mathrm{ms}^{2}\right)$ & $13754.15 \pm 7230.44$ & $17284.83 \pm 9773.87$ & \\
\hline $\operatorname{Ln}(\mathrm{ULF})$ & $9.39 \pm 0.55$ & $9.61 \pm 0.54$ & $\mathrm{~ns}$ \\
\hline 5 -min total power $\left(\mathrm{ms}^{2}\right)$ & $3016.01 \pm 1516.59$ & $3960.45 \pm 1793.87$ & \\
\hline Ln (5-min total power) & $7.87 \pm 0.58$ & $8.19 \pm 0.45$ & 0.01 \\
\hline 5-min VLF $\left(\mathrm{ms}^{2}\right)$ & $1829.91 \pm 896.27$ & $2443.20 \pm 1091.84$ & \\
\hline $\operatorname{Ln}(5-\min \mathrm{VLF})$ & $7.38 \pm 0.54$ & $7.70 \pm 0.45$ & 0.01 \\
\hline $5-\min \operatorname{LF}\left(\mathrm{ms}^{2}\right)$ & $817.92 \pm 542.88$ & $1204.97 \pm 573.14$ & \\
\hline $\operatorname{Ln}(5-\min \mathrm{LF})$ & $6.49 \pm 0.70$ & $6.98 \pm 0.52$ & 0.01 \\
\hline $5-\min \mathrm{HF}\left(\mathrm{ms}^{2}\right)$ & $368.18 \pm 325.90$ & $312.28 \pm 253.51$ & \\
\hline $\operatorname{Ln}(5-\min \mathrm{HF})$ & $5.48 \pm 1.02$ & $5.44 \pm 0.81$ & ns \\
\hline $\mathrm{LF} / \mathrm{HF}$ ratio & $3.42 \pm 2.26$ & $5.46 \pm 3.48$ & \\
\hline $\mathrm{Ln}(\mathrm{LF} / \mathrm{HF}$ ratio) & $1.02 \pm 0.68$ & $1.53 \pm 0.58$ & 0.001 \\
\hline Normalized LF (nu) & $71.88 \pm 11.28$ & $80.18 \pm 7.11$ & 0.001 \\
\hline Normalized HF (nu) & $28.12 \pm 11.28$ & $19.82 \pm 7.11$ & 0.001 \\
\hline Sleep cycle duration $(\mathrm{h})$ & $7.40 \pm 1.27$ & $7.42 \pm 0.94$ & ns \\
\hline
\end{tabular}

\footnotetext{
${ }^{a} P$ values from single factor ANOVA $F$ statistic.
} 


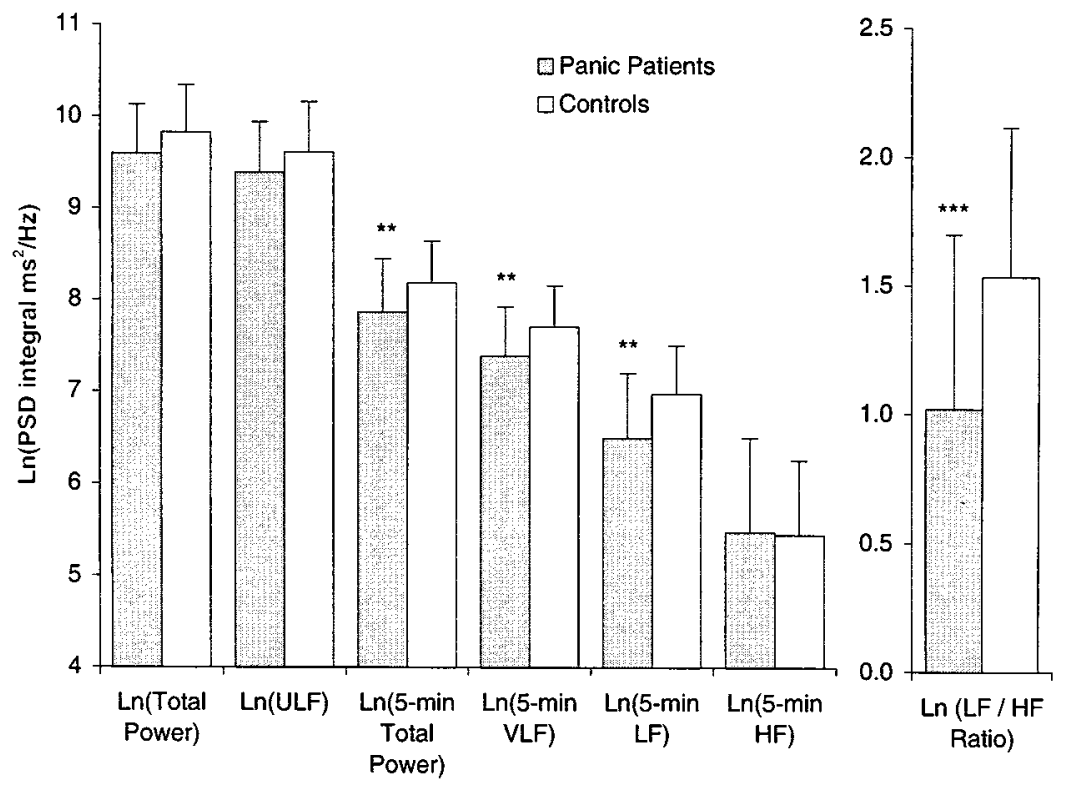

Fig. 1. Frequency domain 24-h HRV measures in patients with panic disorder $(n=38)$ as compared to age- and gender-matched healthy controls $(n=38)$. ${ }^{* *} P<0.01, * * * P<0.001$.

\subsection{Awake and sleep differences}

Table 2 displays mean values for all HRV measures during the daytime hours (09:00-20:00 h), during sleep, and the night-day differences. As shown in the table, panic patients had a significantly greater night-day difference in the SDNN index, RMS-SD, 5-min total power and VLF power than did control subjects $(P<0.05)$. Due to this larger increase in HRV in the panic patients during the sleep period, the SDNN index, 5-min total power and VLF power were significantly lower relative to healthy controls only during the waking hours $(P<0.001)$, whereas sleep values for these measures were not significantly different. Conversely, the SDNN was significantly lower in PD patients during the sleep period $(P<0.05)$ but not during the waking hours, while LF power was significantly lower during both the waking $(P<0.0001)$ and sleep $(P<0.05)$ periods. Absolute HF power did not differ between the two groups during either the waking or sleep periods.

In terms of normalized power and the $\mathrm{LF} / \mathrm{HF}$ ratio, both of which are considered indices of ANS balance, the normalized LF power and the LF/HF ratio were significantly lower in panic patients as compared to control subjects during both the waking hours (normalized LF, $P<0.001$; LF $/ \mathrm{HF}$ ratio, $P<0.01$ ) and during sleep $(P<0.01)$. Normalized HF power was significantly higher in patients during both the waking $(P<0.001)$ and sleep $(P<0.01)$ periods. 
Table 2

Comparison of awake and sleep data ${ }^{\mathrm{a}}$

\begin{tabular}{|c|c|c|c|c|c|c|c|c|c|}
\hline & \multicolumn{2}{|c|}{ Daytime (09:00-20:00 h) } & $P<$ & \multicolumn{2}{|c|}{ Nighttime (actual reported sleep time) } & $P<$ & \multicolumn{2}{|c|}{ Night-day difference } & $P<$ \\
\hline $\begin{array}{l}\text { Mean heart rate } \\
\text { (BPM) }\end{array}$ & $83.87 \pm 11.39$ & $84.10 \pm 8.80$ & - & $67.64 \pm 10.12$ & $66.96 \pm 8.29$ & - & $-16.23 \pm 7.85$ & $-17.15 \pm 7.40$ & - \\
\hline $\begin{array}{l}\text { Mean RR interval } \\
\text { (ms) }\end{array}$ & $741.99 \pm 100.71$ & $736.57 \pm 78.09$ & ns & $913.49 \pm 122.29$ & $922.04 \pm 115.49$ & ns & $171.51 \pm 83.65$ & $185.47 \pm 89.94$ & ns \\
\hline SDNN index (ms) & $50.94 \pm 14.17$ & $62.40 \pm 12.77$ & 0.001 & $61.93 \pm 19.92$ & $65.42 \pm 22.78$ & ns & $10.99 \pm 14.24$ & $3.02 \pm 17.99$ & 0.05 \\
\hline RMS-SD (ms) & $27.49 \pm 12.82$ & $28.23 \pm 8.59$ & & $45.30 \pm 23.62$ & $40.06 \pm 20.58$ & & $17.81 \pm 15.89$ & $11.83 \pm 16.75$ & \\
\hline Ln (RMS-SD) & $3.21 \pm 0.46$ & $3.29 \pm 0.31$ & ns & $3.67 \pm 0.56$ & $3.58 \pm 0.47$ & ns & $0.46 \pm 0.35$ & $0.28 \pm 0.34$ & 0.05 \\
\hline $\begin{array}{l}\text { 5-min total power } \\
\left(\mathrm{ms}^{2}\right)\end{array}$ & $2394.65 \pm 1277.78$ & $3568.38 \pm 1463.15$ & & $3760.75 \pm 2228.10$ & $4596.92 \pm 2834.62$ & & $1366.10 \pm 1737.57$ & $1028.54 \pm 2241.08$ & \\
\hline $\begin{array}{l}\text { Ln }(5 \text {-min total } \\
\text { power) }\end{array}$ & $7.64 \pm 0.55$ & $8.10 \pm 0.42$ & 0.001 & $8.04 \pm 0.68$ & $8.25 \pm 0.62$ & ns & $0.40 \pm 0.42$ & $0.15 \pm 0.47$ & 0.05 \\
\hline Ln (5-min HF) & $5.03 \pm 1.00$ & $5.19 \pm 0.74$ & ns & $5.85 \pm 1.20$ & $5.72 \pm 0.96$ & ns & $0.81 \pm 0.76$ & $0.53 \pm 0.69$ & ns \\
\hline $\mathrm{LF} / \mathrm{HF}$ ratio & $5.49 \pm 2.80$ & $8.24 \pm 4.58$ & & $3.30 \pm 2.72$ & $5.22 \pm 3.82$ & & $-2.20 \pm 2.59$ & $-3.02 \pm 3.75$ & ns \\
\hline Ln (LF/HF ratio) & $1.56 \pm 0.56$ & $1.98 \pm 0.52$ & 0.01 & $0.89 \pm 0.80$ & $1.43 \pm 0.67$ & 0.01 & - & - & \\
\hline $\begin{array}{l}\text { Normalized LF } \\
(\mathrm{nu})\end{array}$ & $76.75 \pm 10.58$ & $83.83 \pm 6.79$ & 0.001 & $62.52 \pm 15.95$ & $72.42 \pm 11.86$ & 0.01 & $-14.23 \pm 12.43$ & $-11.40 \pm 10.22$ & ns \\
\hline $\begin{array}{l}\text { Normalized HF } \\
\quad(\mathrm{nu})\end{array}$ & $23.25 \pm 10.58$ & $16.17 \pm 6.79$ & 0.001 & $37.48 \pm 15.95$ & $27.58 \pm 11.86$ & 0.01 & $14.23 \pm 12.43$ & $11.40 \pm 10.22$ & ns \\
\hline
\end{tabular}

a $P$ values from single factor ANOVA $F$ statistic. 


\subsection{Circadian rhythm analysis}

Fig. 2 compares hourly averages for the RR interval and frequency domain HRV measures in the panic and control groups. Values are shown for each waking hour from 09:00 to 20:00 h. Data points for the 10:00-10:59 h interval are not plotted, for reasons described in Section 2.4. Since all participants did not go to sleep or wake up at the same times, the sleep hours have been normalized in order to correspond to the actual recorded sleep times for each subject.

As seen in the figure, with regard to all frequency domain measures except HF power, panic patients tended to have lower HRV than the control group. Both panic patients and control subjects exhibited significant day-night differences in the HRV measures, with RR interval and overall variability increasing during sleep, as expected. The overall pattern of change in the different HRV measures was relatively similar between the two groups, although the control group tended to have a greater increase in HRV from the beginning to the end of the sleep cycle.

The control group also tended to exhibit a characteristic 'dip' in most HRV measures during the 13:00-14:00 $\mathrm{h}$ interval, which is explained by the fact that most of these subjects were employed by an organization where the regular lunch hour occurred during this time period. As the time at which the panic patients ate lunch varied more widely, as noted by diary entries, this same post-mealtime drop in HRV was not evident in the group means.

\subsubsection{Group effects}

The results of repeated measures ANOVA are displayed in Table 3. The hourly average HRV measurement values for the group factor (panic vs control) were significant for the following measures: 5-min total power $(P<0.01)$, VLF power $(P<0.01)$, LF power $(P<0.001), \mathrm{LF} / \mathrm{HF}$ ratio $(P<0.001)$ and both the HF and LF normalized power measures $(P<0.001)$. As one would expect, these results correlate to the 24-h measures for the same variables.

Table 3

Analysis of hourly HRV values (repeated measures ANOVA)

\begin{tabular}{|c|c|c|c|c|c|c|}
\hline & \multicolumn{2}{|c|}{$\begin{array}{l}\text { Group effect (panic vs } \\
\text { controls }\end{array}$} & \multicolumn{2}{|c|}{$\begin{array}{l}\text { Time effect (hourly } \\
\text { values) }\end{array}$} & \multicolumn{2}{|c|}{$\begin{array}{l}\text { Group versus time effect } \\
\text { (interaction) }\end{array}$} \\
\hline & $F$ & $P<$ & $F$ & $P<$ & $F$ & $P<$ \\
\hline $\begin{array}{l}\text { Mean RR interval } \\
\quad(\mathrm{ms})\end{array}$ & 0.02 & ns & 104.50 & 0.001 & 3.38 & 0.001 \\
\hline $\begin{array}{l}\text { Ln }(5-\mathrm{min} \text { total } \\
\text { power })\end{array}$ & 8.18 & 0.01 & 17.42 & 0.001 & 5.45 & 0.001 \\
\hline $\operatorname{Ln}(5-\min \mathrm{VLF})$ & 9.53 & 0.01 & 15.88 & 0.001 & 4.34 & 0.001 \\
\hline $\operatorname{Ln}(5-\min \mathrm{LF})$ & 11.94 & 0.001 & 9.47 & 0.001 & 3.49 & 0.001 \\
\hline $\operatorname{Ln}(5-\min \mathrm{HF})$ & 0.03 & ns & 28.53 & 0.001 & 4.68 & 0.001 \\
\hline $\mathrm{Ln}(\mathrm{LF} / \mathrm{HF}$ ratio) & 14.13 & 0.001 & 29.73 & 0.001 & 1.27 & ns \\
\hline Normalized LF (nu) & 13.14 & 0.001 & 37.38 & 0.001 & 1.46 & ns \\
\hline Normalized HF (nu) & 13.14 & 0.001 & 37.38 & 0.001 & 1.46 & ns \\
\hline
\end{tabular}



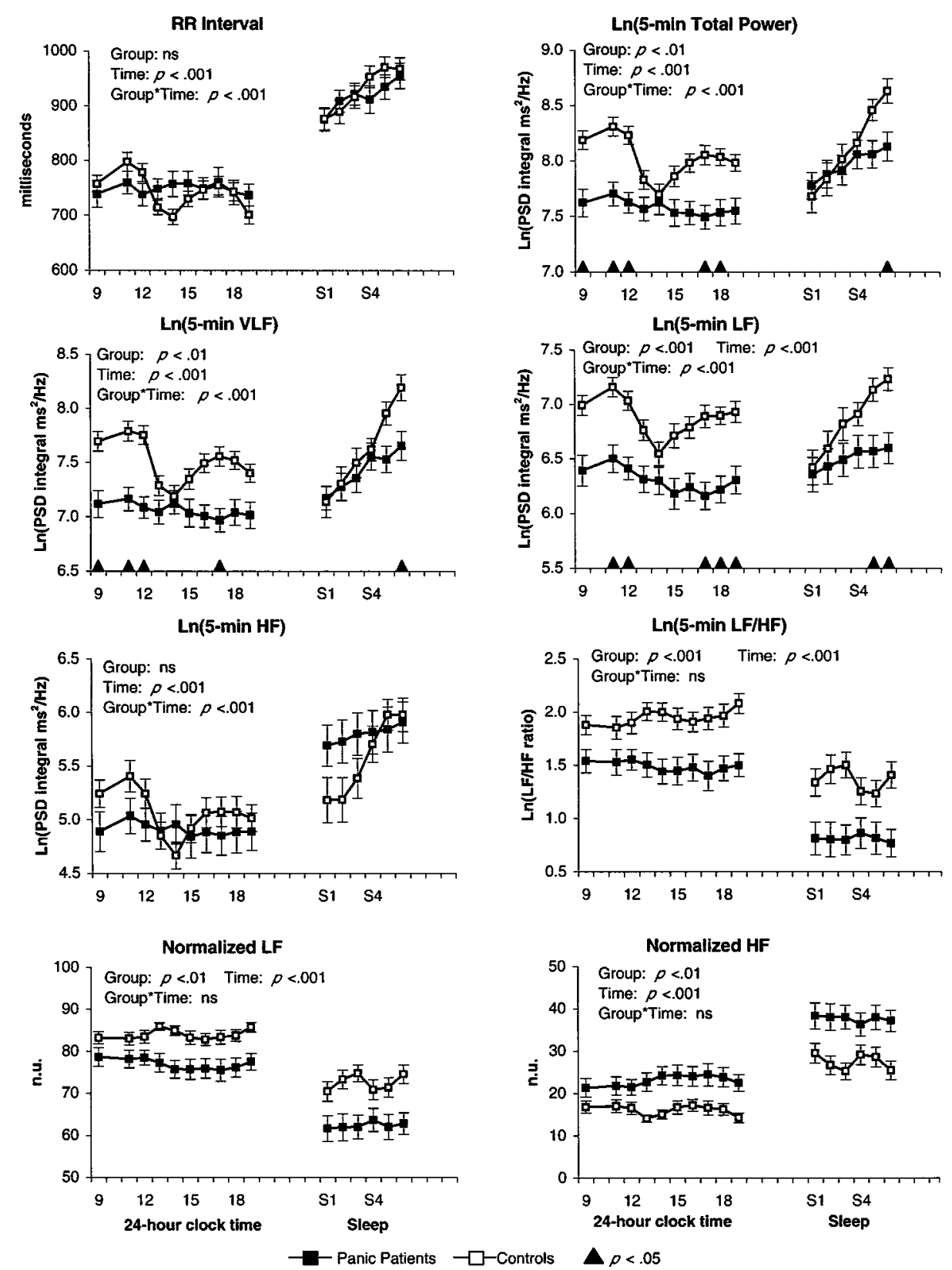

Fig. 2. Mean hourly values for HRV measures over a 24-h period in patients with panic disorder $(n=38)$ as compared to healthy controls $(n=38)$. Waking hours $(09: 00-20: 00 \mathrm{~h})$ are displayed as 24 -h clock time, while sleep hours have been normalized so as to correspond to actual reported sleep time. The $\boldsymbol{\Delta}$ symbol marks hourly intervals during which values differed significantly between the two groups $(P<0.05)$. Result of repeated measures ANOVA are also displayed at the top of each graph. 


\subsubsection{Time effects}

The time factor was significantly different for all eight measures: RR interval, 5-min total power, VLF, LF, HF, LF/HF ratio, normalized LF and normalized HF $(P<0.001)$ (Table 3). Sidak's post-hoc analysis of the time factor showed that all nighttime (sleep) RR interval epochs were significantly longer (lower HR) than all daytime hours $(P<0.05)$. The RR intervals for the first sleep epoch $(\mathrm{S} 1)$ were significantly shorter than for epochs $\mathrm{S} 4,5$ and $6(P<0.05)$. S2 was shorter than S5 and S6 $(P<0.05)$. This illustrates a significant lengthening of the RR interval (heart rate slowing) as the night progressed.

The 5-min total power $(5 \mathrm{mTP})$ during the daytime was highest at 11:00 h, and was significantly higher $(P<0.05)$ than the 13:00 through 17:00 $(13: 00-17: 00 \mathrm{~h})$ interval and 19:00 h. At 14:00 h, 5mTP was lower $(P<0.05)$ than the morning hours (09:00-12:00 h). During sleep 5mTP climbed steadily. By the third sleep epoch (S3), the value was higher than the 13:00-15:00 h values $(P<0.05)$. The fourth sleep epoch was higher than the 13:00-19:00 h values $(P<0.05)$, and S5 was higher than the 12:00-19:00 $\mathrm{h}$ values $(P<0.05)$. The last sleep epoch $(\mathrm{S} 6)$ was higher than all daytime hourly values $(P<0.05)$. This upward-sloping trend was also significant within the sleep cycle itself; by S4, 5mTP was already higher than during $\mathrm{S} 1$ and $\mathrm{S} 2(P<0.05)$. S5 was higher $(P<0.05)$ than $\mathrm{S} 1-\mathrm{S} 3$, and $\mathrm{S} 6$ was higher than $\mathrm{S} 1-\mathrm{S} 4(P<0.05)$.

The 5-min VLF power ( $5 \mathrm{mVLF}$ ) exhibited a circadian pattern very similar to that of 5mTP. During the daytime hours, $5 \mathrm{mVLF}$ was highest at 11:00 h, significantly higher than the 13:00-15:00, 19:00 $\mathrm{h}$ and S1 values $(P<0.05)$. During sleep, $5 \mathrm{mVLF}$ power climbed steadily; by $\mathrm{S} 4$ the level was higher than the 13:00-19:00 $\mathrm{h}$ values $(P<0.05)$. S5 was greater than the $12: 00-19: 00 \mathrm{~h}$ values $(P<0.05)$, and by S6 the value was higher than all daytime hourly values $(P<0.05)$. As with $5 \mathrm{mTP}$, this upward-sloping trend was significant within the sleep cycle itself; by $\mathrm{S} 4$, $5 \mathrm{mVLF}$ was higher than $\mathrm{S} 1$ and $\mathrm{S} 2(P<0.05)$. S5 was higher than $\mathrm{S} 1-\mathrm{S} 3(P<0.05)$ and $\mathrm{S} 6$ was higher than $\mathrm{S} 1-\mathrm{S} 4(P<0.05)$.

The 5-min LF power (5mLF) was highest during the 11:00 h, which was significantly higher than the 13:00-18:00 $\mathrm{h}$ and the $\mathrm{S} 1-\mathrm{S} 2$ values $(P<0.05)$. The 14:00 and 15:00 $\mathrm{h}$ values were lower than all the morning values $(09: 00-12: 00 \mathrm{~h})$ $(P<0.05)$. S4 was higher than the $14: 00$ and $15: 00 \mathrm{~h}$ values $(P<0.05)$. S5 values were higher than the 13:00-18:00 h values. During S6, 5mLF was higher than the 13:00-19:00 $\mathrm{h}$ values $(P<0.05)$. Within the sleep cycle there was an upward-sloping trend. S1 was lower than S3-S6 and S2 was lower than S5 and S6 $(P<0.05)$.

For 5-min $\mathrm{HF}$ power $(5 \mathrm{mHF})$, the only significant finding during the daytime was that the 14:00 h value was lower then the 11:00 h value $(P<0.05)$. During the night, $5 \mathrm{mHF}$ during the first and second sleep epochs was higher than the 13:00-19:00 h epochs $(P<0.05)$ and S3 was higher than the 09:00-19:00 $\mathrm{h}$ values $(P<0.05)$, except for the 11:00 h epoch, which was the highest daytime value. Within the sleep cycle the upward trend reached significance by the last two sleep epochs; S5 and S6 were both higher than S1 and S2 $(P<0.05)$.

The $\mathrm{LF} / \mathrm{HF}$ ratio, normalized LF and normalized $\mathrm{HF}$ power all exhibited the same pattern. All daytime hourly values were significantly different than all 
nighttime values. The $\mathrm{LF} / \mathrm{HF}$ ratio and normalized LF nighttime values were all lower than the daytime values $(P<0.05)$. Normalized HF nighttime values were higher than all daytime values $(P<0.05)$.

\subsubsection{Group versus time effects}

The group versus time factor was significant for the following: RR interval, 5-min total power, VLF, LF, and HF power $(P<0.05)$ (Table 3). A significant group versus time interaction denotes that the two groups did not parallel each other over time. Results of the separate hourly ANOVAs are indicated in Fig. 2 by a solid triangle placed on the time axis for each hour during which the two groups differed significantly $(P<0.05)$.

For RR interval and HF power, none of the individual hourly values differed significantly between the two groups. For 5mTP, the 09:00-12:00 and 17:00-18:00 $\mathrm{h}$ values were lower in the panic group $(P<0.05)$. The last sleep epoch (S6) was also lower in the panic group $(P<0.05)$. The 5-min VLF exhibited a similar pattern, with the 09:00-12:00 and 17:00 $\mathrm{h}$ values as well as the last sleep epoch (S6) values being lower in the panic group $(P<0.05)$. For $5 \mathrm{mLF}$ power, the 11:00, 12:00, and 17:00-19:00 $\mathrm{h}$ values were lower in the panic group $(P<0.05)$. Additionally, the $5 \mathrm{mLF}$ values were significantly lower in the panic group during the latter part of the sleep cycle (S5 and S6) $(P<0.05)$.

\section{Discussion}

Overall, the results of this study are in accordance with previous reports indicating decreased HRV in individuals with panic disorder. PD patients had significantly lower 5-min total power, VLF and LF power as compared to healthy age and gender-matched controls over a 24-h period. The SDNN index, which correlates to the frequency domain measures of 5-min total power and VLF power, was also significantly lower in the patients, while the SDNN was significantly lower in the patients during sleep only. In addition, panic patients had significantly reduced normalized LF power, increased normalized HF power and a lower LF/HF ratio over the $24 \mathrm{~h}$ as compared to control subjects. These significant differences in HRV occurred despite the fact that mean HR was comparable in patients and controls. Collectively, these results suggest that sympathetic nervous system activity is depressed in patients with panic disorder and that patients exhibit a relative predominance of parasympathetic activity during normal daily life. The circadian rhythm analysis revealed that significant differences in 5-min total power, VLF and LF power occurred during some of the daytime hours as well as during the last hours of sleep.

When compared to the previous analysis of Holter ECG records in PD patients conducted by Yeragani et al. (1998), our results exhibit some important similarities as well as several differences. In accordance with our data, Yeragani's group also found a normal mean RR interval, normal HF power and significantly decreased VLF power in panic patients. Yeragani's study reported significantly lower 24-h 
total power and ULF power in patients, with differences being more pronounced during sleep. The $24 \mathrm{~h}$ total power $(P=0.06)$ and ULF power $(P=0.08)$ also tended to be lower in patients in our investigation, although the differences did not reach significance. However, the SDNN, which correlates to total and ULF power, was significantly lower during sleep in patients in our study, which is consistent with Yeragani's findings. In contrast to our results, no significant differences were observed in absolute LF power or in the $\mathrm{LF} / \mathrm{HF}$ ratio in the former study. However, there was a nonsignificant trend toward decreased LF power in PD patients in Yeragani's data. Also in contrast to our findings, the former study found VLF power to be significantly lower in patients only during sleep, whereas in our study, in terms of awake/sleep comparisons, VLF power was significantly lower in patients during the daytime only.

Some of the factors that can influence HRV are age (Umetani et al., 1998), heart rate, physical activity, various forms of heart disease and diabetic neuropathy (Malik and Camm, 1995; HRV Task Force Report, 1996). Our findings cannot be explained on the basis of age differences between the groups, or by any known physical illness. Mean heart rate over the recording period was not significantly different in patients versus controls, and subjects' activity logs indicated that levels of physical activity were also comparable between the two groups.

In a previous study on the effects of age and gender on HRV, we found that all measures of HRV decline with aging, with measure-dependent patterns (Umetani et al., 1998). Measures reflecting parasympathetic activity decline the fastest, stabilizing after age 60. Nevertheless, the age of our sample was well within the range that age-related declines in HRV would be insufficient to mask any potential differences between the groups in the RMS-SD or 24-h HF power. Furthermore, the fact that lower frequency HRV measures decline at a slower rate than high frequency measures suggests that our main findings of lowered VLF, LF and 5-min total power in panic patients were not influenced by age-related patterns of HRV decline.

Several studies have suggested that in response to specific short-term laboratoryadministered autonomic nervous system challenges, individuals with panic disorder as well as nonclinical panic experience exaggerated sympathetic activation and/or vagal withdrawal, leading to a relative sympathetic predominance (Weissman et al., 1987; Yeragani et al., 1990, 1994; Townsend et al., 1998). Similar results were obtained in investigations that aimed to assess dynamic autonomic control by aggregating data across multiple laboratory tasks designed to elicit diverse ANS responses (Friedman et al., 1993; Friedman and Thayer, 1998a). In contrast to these short-term findings, our data indicate that outside the laboratory and under the conditions of usual daily life over a 24-h period, sympathetic function is depressed while parasympathetic activity remains normal in PD patients, leading to a relative parasympathetic predominance. We would like to emphasize that our findings are not necessarily inconsistent with those of the cited short-term studies. It is quite conceivable that PD patients may exhibit increased vagal withdrawal and/or enhanced sympathetic reactivity in response to certain types of stimuli, while under nonchallenging conditions, the sympathetic system remains depressed and vagal tone normal. 
Alternatively, contrasting results between some short-term investigations and our own and Yeragani's 24-h data may be due to age differences in the patient groups assessed. Specifically, the average age of our PD sample (38) and Yeragani's (36) was higher than the mean age of patient groups that demonstrated increased VLF power (e.g. Rechlin et al., 1994: mean age =31) or decreased HF power (e.g. Friedman and Thayer, 1998a: mean age $=19$ ) in short-term studies. Thus, it may be possible, although unlikely, that the autonomic profile of PD patients shifts with age from lowered parasympathetic activity and predominant sympathetic control at younger ages to predominant vagal control and lowered sympathetic activity at older ages.

Certainly, further investigation with patients of differing ages, or following a PD sample over time, would be required to validate or refute this possibility. However, if bouts of sympathetic hyperrarousal are indeed implicated in the dramatic elevations in heart rate, blood pressure and other alarming somatic symptoms generally observed in panic attacks (Friedman and Thayer, 1998b; Wilkinson et al., 1998), it is possible that these repeated surges of overactivity could, over time, lead to depletion or exhaustion of the sympathetic efferent system and/or the adrenalmedullary system, resulting in depressed $\mathrm{HRV}$ in the lower frequency ranges. Recent findings in the neurocardiology literature in fact provide support for a potential link between depleted catecholamine levels and lowered HRV in the ULF and VLF range, indicating that the heart's intrinsic nervous system is primarily responsive to circulating epinephrine (Armour, 1997). As epinephrine levels follow a circadian rhythm, and the day/night circadian rhythm is the primary contributor in the generation of both the SDNN and ULF rhythms, low levels of circulating epinephrine could result in a low SDNN, especially during the nighttime period.

Earlier attempts to characterize panic in terms of ANS disturbances have linked this disorder with chronic autonomic hyperrarousal (Lader and Mathews, 1970; Roth et al., 1986), or, alternatively, with excess autonomic lability (i.e. chronic and extreme fluctuation from a homeostatic norm) (Eysenck, 1970; Costello, 1971). This latter explanation persists in the current literature in both cognitive and conditioning models of panic (Wolpe and Rowan, 1988; Anastasiades et al., 1990). The present study, on the other hand, supports the newly emerging view that ANS function in PD is not accurately described by either of these models (Friedman and Thayer, 1998b). Our data indicate that baseline autonomic activity is not chronically elevated in panic patients. Further, our results suggest that autonomic variability is reduced rather than abnormally augmented in individuals with PD.

The finding of lowered HRV in PD patients is in accordance with contemporary systems-oriented models of psychophysiological regulation that emphasize flexible responsivity as the foundation of stability (Appel et al., 1989; West, 1990; Friedman and Thayer, 1998b). In contrast to the classical homeostatic model, in which the maintenance of internal constancy in the face of external perturbations is seen as the hallmark of healthy function (Cannon, 1932), systems models view patterns of organized physiological variability to confer the physiological and behavioral adaptability necessary to respond effectively to changing environmental demands. Thus, high variability in heart rate is considered a marker of system integrity and 
stress resiliency, whereas reduced variability can often be indicative of suboptimal functioning or pathology (Appel et al., 1989; Lipsitz and Goldberger, 1992; Porges, 1992a; Peng et al., 1994). In line with this model, diminished HRV has been found to characterize numerous and widely diverse pathological conditions (Öri et al., 1992; Malik and Camm, 1995). Reduced HRV has also been linked with compromised self-regulatory psychological functions, including diminished attentional capacity and emotional regulation (Porges, 1991, 1992b; Porges et al., 1994).

Within the above framework, it would be predicted that low HRV would be found in individuals with panic disorder, a psychophysiological condition which represents a severe limitation on the range and complexity of physiological, behavioral and emotional responses to stress (Friedman and Thayer, 1998b). Consistent with this view are findings indicating a relationship between HRV and the severity of psychological status in PD patients. For example, Yeragani and colleagues found a significant negative correlation between trait anxiety scores and 24-h ULF and total power in panic patients (Yeragani et al., 1998). Middleton and Ashby noted a diminished spectral peak in the range of $0.1 \mathrm{~Hz}$ in patients and reported a significant rise in HRV in this frequency range upon clinical recovery from PD following either pharmacological treatment or cognitive therapy (Middleton et al., 1994; Middleton and Ashby, 1995). These findings and those of the present study add to the growing body of evidence illuminating a relationship between HRV patterns and mental and emotional variables (Pagani et al., 1991; Sloan et al., 1994a,b; McCraty et al., 1995; Tiller et al., 1996), and linking chronic alternations in these patterns with psychopathology (Dalack and Roose, 1990; Rechlin et al., 1994; Thayer et al., 1996). Collectively, results suggest that low HRV may be a common characteristic of several psychological disorders (e.g. PD, generalized anxiety disorder and depression), all of which can be described by a compromised ability to modulate one's emotional, behavioral and physiological responses to environmental challenges.

In addition to compromised psychological functioning, panic disorder has been linked with heightened susceptibility to cardiovascular illness and excess mortality from cardiovascular causes (Coryell et al., 1982, 1986; Weissman et al., 1990; Kawachi et al., 1994) Epidemiological studies have also found significant comorbidity between PD and various respiratory, gastrointestinal and neurological illnesses (Zaubler and Katon, 1996). As diminished HRV has been identified as a predictor of increased risk of cardiovascular disease as well as mortality from both cardiac and non-cardiac causes (Tsuji et al., 1994, 1996; Dekker et al., 1997), it is likely that reduced HRV in PD patients may contribute to the increased rates of morbidity and mortality in this patient population.

In conclusion, the present study confirms and extends previous findings of compromised autonomic function in panic disorder, as evidenced by reduced HRV. Whereas data from some studies assessing various cardiovascular and HRV parameters from short-term recordings have been interpreted as support for a role of low cardiac vagal tone in PD, 24-h HRV analyses provide evidence that vagal tone is normal under conditions of usual daily life, whereas sympathetic activity appears to be depressed. 
Additional studies using larger sample sizes and employing more uniform analysis methods are clearly required to reconcile the inconsistencies still existing in the current literature on autonomic function in panic disorder. However, the data collected to date suggest that this condition may be characterized by episodes of accentuated sympathetic reactivity and/or vagal withdrawal in response to certain challenges, coupled with low baseline sympathetic tone under nonchallenging conditions. Findings of low HRV in PD are consistent with contemporary models of psychophysiological regulation in nonlinear dynamical systems, and support the emerging portrait of PD as a disorder involving reduced flexibility and adaptability across biological, affective and behavioral dimensions. These findings are also in line with the higher illness and mortality rates found in individuals with PD. Finally, results add to the growing body of data confirming the value of HRV analysis as a sensitive tool to explore the relationships between autonomic dysfunction and psychopathology.

\section{Acknowledgements}

The authors gratefully acknowledge Student Research Fellows Colette N. Meyer and Hayes H. Stuppy for the collection, compilation and verification of the patient records and data from which this paper was generated.

\section{References}

American Psychiatric Association, 1994. Diagnostic and Statistical Manual of Mental Disorders, fourth ed. American Psychiatric Association, Washington, DC.

Anastasiades, P., Clark, D., Salkovskis, P., Middleon, H., Hackman, A., Johnston, D., 1990. Psychophysiological responses in panic and stress. J. Psychophysiol. 4, 331-338.

Appel, M.L., Berger, R.D., Saul, P., Smith, J., Cohen, R., 1989. Beat to beat variability in cardiovascular variables: noise or music? J. Am. Coll. Cardiol. 14, 1139-1148.

Armour, J.A., 1997. Intrinsic cardiac neurons involved in cardiac regulation possess alpha 1-, alpha 2-, beta 1- and beta 2-adrenoceptors. Can. J. Cardiol. 13, 277-284.

Barrios-Choplin, B., Atkinson, M., 1996. Personal and Organizational Quality Assessment. Institute of HeartMath, Boulder Creek, CA.

Bigger, J.T., Fleiss, J.L., Steinman, R.C., Rolnitzky, L.M., Schneider, W.J., Stein, P.K., 1995. RR variability in healthy, middle-aged persons compared with patients with chronic coronary heart disease or recent acute myocardial infarction. Circulation 91, 1936-1943.

Cannon, W., 1932. The Wisdom of the Body. W.W. Norton, New York.

Coryell, W., Noyes, R., Clancy, J., 1982. Excess mortality in panic disorder. A comparison with primary unipolar depression. Arch. Gen. Psychiatry 39, 701-703.

Coryell, W., Noyes, R. Jr, House, J.D., 1986. Mortality among outpatients with anxiety disorders. Am. J. Psychiatry 143, 508-510.

Costello, C., 1971. Anxiety and the persisting novelty of input from the autonomic nervous system. Behav. Ther. 2, 321-333.

Dalack, G.W., Roose, S.P., 1990. Perspectives on the relationship between cardiovascular disease and affective disorder. J. Clin. Psychiatry 51 (Suppl.), 4-11.

Dekker, J.M., Schouten, E.G., Klootwijk, P., Pool, J., Swenne, C.A., Kromhout, D., 1997. Heart rate variability from short electrocardiographic recordings predicts mortality from all causes in middleaged and elderly men. The Zutphen Study. Am. J. Epidemiol. 145, 899-908. 
Derogatis, L., 1993. Brief Symptom Inventory. National Computer Systems, Minneapolis.

Eckberg, D.L., 1997. Sympathovagal balance: a critical appraisal. Circulation 96, 3224-3232.

Eysenck, H., 1970. The Structure of Human Personality. Methuen, London.

Friedman, B.H., Thayer, J.F., 1998a. Anxiety and autonomic flexibility: a cardiovascular approach. Biol. Psychol. 49, 303-323.

Friedman, B.H., Thayer, J.F., 1998b. Autonomic balance revisited: panic anxiety and heart rate variability. J. Psychosom. Res. 44, 133-151.

Friedman, B.H., Thayer, J.F., Borkovec, T.D., Tyrrell, R.A., Johnson, B.H., Columbo, R., 1993. Autonomic characteristics of nonclinical panic and blood phobia. Biol. Psychiatry 34, 298-310.

Hamada, T., Koshino, Y., Misawa, T., Isaki, K., Gejyo, F., 1998. Mitral valve prolapse and autonomic function in panic disorder. Acta Psychiatrica Scand. 97, 139-143.

Kawachi, I., Sparrow, D., Vokonas, P.S., Weiss, S.T., 1994. Symptoms of anxiety and risk of coronary heart disease. The Normative Aging Study. Circulation 90, 2225-2229.

Kitney, R., Rompelman, O., 1977. Analysis of the human blood pressure and thermal control systems. In: Perkins, W.J. (Ed.), Biomedical Computing. University Park Press, Baltimore, pp. 49-50.

Kleiger, R.E., Stein, P.K., Bosner, M.S., Rottman, J.N., 1992. Time domain measurements of heart rate variability. Ambul. Electrocardiogr. 10, 487-498.

Klein, E., Cnaani, E., Harel, T., Braun, S., Ben-Haim, S., 1995. Altered heart rate variability in panic disorder patients. Soc. Biol. Psychiatry 37, 18-24.

Lader, M., Mathews, A., 1970. Physiological changes during spontaneous panic attacks. J. Psychosom. Res. 14, 377-382.

Lipsitz, L.A., Goldberger, A.L., 1992. Loss of 'complexity' and aging. Potential applications of fractals and chaos theory to senescence. J. Am. Med. Assoc. 267, 1806-1809.

Malik, M., Camm, A.J. (Eds.), 1995. Heart Rate Variability. Futura Publishing Company, Armonk, NY.

Malliani, A., 1995. Association of heart rate variability components with physiological regulatory mechanisms. In: Malik, M., Camm, A.J. (Eds.), Heart Rate Variability. Futura Publishing Company, Armonk, NY, pp. 173-188.

Malliani, A., Pagani, M., Lombardi, F., Cerutti, S., 1991. Cardiovascular neural regulation explored in the frequency domain. Circulation 84, 482-492.

McCraty, R., Atkinson, M., Tiller, W.A., Rein, G., Watkins, A., 1995. The effects of emotions on short term heart rate variability using power spectrum analysis. Am. J. Cardiol. 76, 1089-1093.

Middleton, H.C., Ashby, M., 1995. Clinical recovery from panic disorder is associated with evidence of changes in cardiovascular regulation. Acta Psychiatrica Scand. 91, 108-113.

Middleton, H.C., Ashby, M., Robbins, T.W., 1994. Reduced plasma noradrenaline and abnormal heart rate variability in resting panic disorder patients. Biol. Psychiatry 36, 847-849.

Öri, Z., Monir, G., Weiss, J., Sayhouni, X., Singer, D.H., 1992. Heart rate variability: frequency domain analysis. Ambul. Electrocardiogr. 10, 499-537.

Pagani, M., Mazzuero, G., Ferrari, A., Liberati, D., Cerutti, S., Vaitl, D., Tavazzi, L., Malliani, A., 1991. Sympathovagal interaction during mental stress. A study using spectral analysis of heart rate variability in healthy control subjects and patients with a prior myocardial infarction. Circulation 83 (Suppl. II), II/43-II/51.

Pagani, M., Lombardi, F., Guzzette, S., 1986. Power spectral analysis of heart rate and arterial pressure variabilities as a marker of sympatho-vagal interaction in man and conscious dog. Circ. Res. 59, $178-184$.

Peng, C.K., Buldyrev, S.V., Hausdorff, J.M., Havlin, S., Mietus, J.E., Simons, M., Stanley, H.E., Goldberger, A.L., 1994. Non-equilibrium dynamics as an indispensable characteristic of a healthy biological system. Integr. Physiol. Behav. Sci. 29, 283-293.

Perini, R., Orizio, C., Baselli, G., 1990. The influence of exercise intensity on power spectrum of heart rate variability. Eur. J. Appl. Physiol. 61, 143-148.

Pomeranz, B., Macaulay, J.B., Caudill, M.A., 1985. Assessment of autonomic function in humans by heart rate spectral analysis. Am. J. Physiol. 248, H151-H158.

Porges, S.W., 1991. Vagal tone: an autonomic mediator of affect. In: Garber, J., Dodge, K. (Eds.), The Development of Affect Regulation and Dysregulation. Cambridge University Press, New York, pp. 111-128. 
Porges, S.W., 1992a. Autonomic regulation and attention. In: Hayne, H., Richardson, R. (Eds.), Attention and Information Processing in Infants and Adults. Erlbaum, Hillsdale, NJ, pp. 201-223.

Porges, S.W., 1992b. Vagal tone: a physiologic marker of stress vulnerability. Pediatrics 90 (3 pt 2), 498-504.

Porges, SW., Doussard-Roosevelt, J.A., Maiti, A.K., 1994. Vagal tone and the physiological regulation of emotion. In: Fox, N.A. (Ed.), The Development of Emotion Regulation: Behavioral and Biological Considerations. Monographs of the Society for Research in Child Development, vols. 59 (2-3 Serial No. 240). University of Chicago Press, Chicago, pp. 167-186.

Rechlin, T., Weis, M., Spitzer, A., Kaschka, W.P., 1994. Are affective disorders associated with alterations of heart rate variability? J. Affect. Disord. 32, 271-275.

Roth, W.T., Telch, M.J., Taylor, C.B., Sachitano, J.A., Gallen, C.C., Kopell, M.L., McClenahan, K.L., Agras, W.S., Pfefferbaum, A., 1986. Autonomic characteristics of agoraphobia with panic attacks. Biol. Psychiatry 21, 1133-1154.

Saul, J.P., Arai, Y., Berger, R.D., Lilly, L.S., Colucci, W.S., Cohen, R.J., 1988. Assessment of autonomic regulation in chronic congestive heart failure by heart rate spectral analysis. Am. J. Cardiol. 61, 1292-1299.

Seier, F.E., Kellner, M., Yassouridis, A., Heese, R., Strian, F., Wiedemann, K., 1997. Autonomic reactivity and hormonal secretion in lactate-induced panic attacks. Am. J. Physiol. 272 (6 Pt 2), H2630-H2638.

Sloan, R.P., Shapiro, P.A., Bagiella, E., Boni, S.M., Paik, M., Bigger, J.T., Steinman, R.C., Gorman, J.M., 1994a. Effect of mental stress throughout the day on cardiac autonomic control. Biol. Psychol. 37, 89-99.

Sloan, R.P., Shapiro, P.A., Bigger, J.T., Bagiella, E., Steinman, R.C., Gorman, J.M., 1994b. Cardiac autonomic control and hostility in healthy subjects. Am. J. Cardiol. 74, 298-300.

Stein, M.B., Asmundson, G.J., 1994. Autonomic function in panic disorder: cardiorespiratory and plasma catecholamine responsivity to multiple challenges of the autonomic nervous system. Biol. Psychiatry 36, 548-558.

Task Force of the European Society of Cardiology and the North American Society of Pacing and Electrophysiology, 1996. Heart rate variability: standards of measurement, physiological interpretation, and clinical use. Circulation 93, 1043-1065.

Thayer, J.F., Friedman, B.H., Borkovec, T.D., 1996. Autonomic characteristics of generalized anxiety disorder and worry. Soc. Biol. Psychiatry 39, 255-266.

Tiller, W., McCraty, R., Atkinson, M., 1996. Cardiac coherence: a new, noninvasive measure of autonomic nervous system order. Altern. Ther. Health Med. 2, 52-65.

Townsend, M.H., Bologna, N.B., Barbee, J.G., 1998. Heart rate and blood pressure in panic disorder, major depression, and comorbid panic disorder with major depression. Psychiatry Res. 79, 187-190.

Tsuji, H., Venditti, F.J. Jr, Manders, E.S., Evans, J.C., Larson, M.G., Feldman, C.L., Levy, D., 1994. Reduced heart rate variability and mortality risk in an elderly cohort. The Framingham Heart Study. Circulation 90, 878-883.

Tsuji, H., Larson, M.G., Venditti, F.J. Jr, Manders, E.S., Evans, J.C., Feldman, C.L., Levy, D., 1996. Impact of reduced heart rate variability on risk for cardiac events. The Framingham Heart Study. Circulation 94, 2850-2855.

Umetani, K., Singer, D.H., McCraty, R., Atkinson, M., 1998. Twenty-four hour time domain heart rate variability and heart rate: relations to age and gender over nine decades. J. Am. Coll. Cardiol. 31, 593-601.

Weissman, M.M., 1991. Panic disorder: impact on quality of life. J. Clin. Psychiatry 52 (Suppl. 2), 6-9.

Weissman, N.J., Shear, M.K., Kramer-Fox, R., Devereux, R.B., 1987. Contrasting patterns of autonomic dysfunction in patients with mitral valve prolapse and panic attacks. Am. J. Med. 82, $880-888$.

Weissman, M.M., Markowitz, J.S., Ouellette, R., Greenwald, S., Kahn, J.P., 1990. Panic disorder and cardiovascular/cerebrovascular problems: results from a community survey. Am. J. Psychiatry 147, 1504-1508.

West, B., 1990. Fractal Physiology and Chaos in Medicine. World Scientific, Teaneck, NJ. 
Wilkinson, D.J., Thompson, J.M., Lambert, G.W., Jennings, G.L., Schwarz, R.G., Jefferys, D., Turner, A.G., Esler, M.D., 1998. Sympathetic activity in patients with panic disorder at rest, under laboratory mental stress, and during panic attacks. Arch. Gen. Psychiatry 55, 511-520.

Wolpe, J., Rowan, V.C., 1988. Panic disorder: a product of classical conditioning. Behav. Res. Ther. 26, $441-450$.

Yeragani, V.K., Balon, R., Pohl, R., Ramesh, C., Glitz, D., Weinberg, P., Merlos, B., 1990. Decreased R-R variance in panic disorder patients. Acta Psychiatrica Scand. 81, 554-559.

Yeragani, V.K., Pohl, R., Balon, R., Ramesh, C., Glitz, D., Jung, I., Sherwood, P., 1991. Heart rate variability in patients with major depression. Psychiatry Res. 37, 35-46.

Yeragani, V.K., Pohl, R., Berger, R., Balon, R., Ramesh, C., Glitz, D., Srinivasan, K., Weinberg, P., 1993. Decreased HRV in panic disorder patients: a study of power-spectral analysis of heart rate. Psychiatry Res. 46, 89-103.

Yeragani, V.K., Srinivasan, K., Balon, R., Ramesh, C., Berchou, R., 1994. Lactate sensitivity and cardiac cholinergic function in panic disorder. Am. J. Psychiatry 151, 1226-1228.

Yeragani, V.K., Sobolewski, E., Igel, G., Johnson, C., Jampala, V.C., Kay, J., Hillman, N., Yeragani, S., Vempati, S., 1998. Decreased heart-period variability in patients with panic disorder: a study of Holter ECG records. Psychiatry Res. 78, 89-99.

Zaubler, T.S., Katon, W., 1996. Panic disorder and medical comorbidity: a review of the medical and psychiatric literature. Bull. Menninger Clin. 60 (Suppl. 2A), A12-A38. 